\title{
ANALISIS FAKTOR-FAKTOR YANG MEMENGARUHI PRODUKTIVITAS DAN KELAYAKAN USAHATANI PADI SAWAH
}

\author{
AN ANAL YSIS OF FACTORS THAT AFFECTS RICE FIELD FARMING \\ PRODUCTIVITY AND FEASIBILITY
}

\section{Carolus Oktavius Rudianto Laim*, Liska Simamora}

\author{
Program Studi Agribisnis, Fakultas Pertanian dan Bisnis, Universitas Kristen Satya Wacana, \\ Salatiga, Jawa Tengah, Indonesia \\ * Email: 522016053@student.uksw.edu \\ (Diterima 12-08-2021; Disetujui 15-12-2021)
}

\begin{abstract}
ABSTRAK
Penelitian ini bertujuan untuk mengetahui faktor-faktor yang memengaruhi produksi usahatani padi sawah (modal, bibit, luas lahan, tenaga kerja, pupuk, pestisida) dan kelayakan usahatani padi sawah di dusun Wonotoro Kecamatan Sambi Boyolali. Data untuk penelitian kuantitatif ini diperoleh dengan metode wawancara dimana pertanyaan sudah tertulis di dalam kuesioner yang disebarkan kepada sampel penelitian. Penetapan sampel dilakukan dengan teknik probability sampling, dengan metode simple random sampling. Jumlah sampel sebanyak 70 orang petani padi sawah. Data dianalisis dengan fungsi produksi Cobb-Douglass. Hasil penelitian menunjukan bahwa faktor produksi luas lahan dan tenaga kerja berpengaruh nyata terhadap produktivitas, sedangkan faktor produksi modal, benih, pupuk, dan pestisida memiliki pengaruh terhadap produktivitas. Hasil analisis kelayakan usahatani didapatkan nilai $\mathrm{R} / \mathrm{C}$ sebesar 1,77 dan $\mathrm{B} / \mathrm{C}$ sebesar 1,06 , kegiatan usahatani sangat layak diusahakan karena dapat meningkatkan aspek finansial. Penggunaan modal dan pupuk yang tepat dapat meningkatkan hasil yang maksimal.
\end{abstract}

Kata kunci : padi sawah, faktor produksi, produktivitas, kelayakan usahatani

\section{ABSTRACT}

This research aims to analyze the production inputs (production capital, seeds, land area, labor, fertilizer, pesticide) that affect production and farming feasibility toward the productivity of rice field farming in Wonotoro Kecamatan Sambi Boyolali village. The data of this quantitative research was collected by using interview where the questions were written inside the questionnaires which have been distributed to the sample of this research. The sample was taken using Probability sampling technique with simple random sampling method. This research has 70 rice farmers as the respondents. The data were analyzed by using Cobb - Douglass production function. The result showed that the production function of land area and labor had a significant effect on productivity, while the production factors of capital, seeds, fertilizers, and pesticides had an effect on productivity. The result of the rice - field farming feasibility analysis shows that $R / C$ ratio is 1,77 and $B / C$ is 1,06 . These addresses to a conclusion that farming activities is absolutely feasible because it could increase the financial aspect. The use of production capital and the right fertilizer could increase maximum result.

Keywords: Rice field, production factors, productivity, farming feasibility

\section{PENDAHULUAN}

Sektor pertanian berperan penting dalam pembangunan ekonomi nasional terutama dalam hal tenaga kerja. (Badan

Pusat Statistik, 2016), menunjukkan

bahwa sektor pertanian menyerap tenaga 


\section{ANALISIS FAKTOR-FAKTOR YANG MEMENGARUHI PRODUKTIVITAS \\ DAN KELAYAKAN USAHATANI PADI SAWAH \\ Carolus Oktavius Rudianto Laim}

kerja sebesar 31,89 persen dalam pembangunan ekonomi nasional dan terus meningkat tiap tahunnya. Produk pertanian yang strategis dalam pembangunan ekonomi indonesia adalah padi. Beras merupakan produk turunan padi yang paling dikonsumsi masyarakat Indonesia, jumlah penduduk yang setiap tahun meningkat menyebabkan produksi beras juga meningkat tiap tahun. Sehingga pemerintah harus menjaga ketersedian beras peningkatan produktivitas dapat menjamin ketersediaan beras nasional.

Jawa Tengah menjadi salah satu sentra produksi padi sawah terbesar kedua setelah Jawa timur. (Badan Pusat Statistik, 2018), menunjukan produksi padi di Jawa Tengah pada tahun 2018 sebesar 9,61 juta ton gabah kering giling (GKG) dan tertinggi pada bulan Maret 2018 dengan luas lahan 0,29 juta hektar dan produktivitas padi sawah sebesar $56,61 \mathrm{kw}$ per hektar serta produksi padi sawah sebesar 0,95 juta ton. Berdasarkan luas panen padi tahun 2018 di Boyolali sebesar 44.757 hektar, Boyolali memproduksi padi yang dikonversi menjadi beras sebesar 138,478 ton beras memberikan kontribusi luas panen 2,38 persen untuk Jawa Tengah, dikarenakan pada bulan Maret - Agustus 2018 terjadi panen raya. Kecamatan Sambi pada tahun 2019 memproduksi padi sebesar 18,709 ton dengan luas lahan panen padi sebesar 3,308 hektar, akan tetapi dusun Wonotoro Kecamatan Sambi pada tahun 2019 mengalami pengurangan hasil panen, hanya menghasilkan 3 ton dengan ratarata produksi $81,60 \quad \mathrm{kw} /$ hektar dikarenakan faktor cuaca dan penyakit pada padi para petani padi sawah menyiasati dengan cara memberikan pupuk dan pestisida yang lebih dari standar (Badan Pusat Statistik, 2019).

Mahananto, et. al., (2009), menyatakan bahwa jumlah pupuk, pestisida, tenaga kerja, luas lahan sangat berpengaruh pada peningkatan produksi padi sawah. Penggunaan faktor produksi berpengaruh pada kegiatan usahatani. Menurut Yuliana, et. al., (2017), penggunaan benih dan pupuk NPK berpengaruh pada produksi padi, sedangkan penggunaan faktor produksi lain seperti pupuk kandang, pupuk urea, pestisida, dan tenaga kerja tidak berpengaruh terhadap produksi, pupuk kandang merupakan yan nilai signifikansinya paling besar. Secara umum peningkatan produksi merupakan indikator keberhasilan usahatani sehingga menjadi tolok ukur kesejahteraan petani, namun tidak menjamin pendapatan yang 
akan diperoleh oleh petani, pendapatan dipengaruhi harga yang diterima petani dan juga biaya input usahatani (Rustam 2014).

Tujuan dari penelitian ini adalah: 1) menganalisis faktor-faktor produksi yang memengaruhi produktivitas padi sawah di dusun Wonotoro Kecamatan Sambi Boyolali, dan 2) menganalisis kelayakan usahatani padi sawah di dusun Wonotoro Kecamatan Sambi Boyolali.

\section{METODE PENELITIAN}

Pengumpulan data dalam penelitian dilakukan di dusun Wonotoro Kecamatan Sambi Kabupaten Boyolali menggunakan teknik wawancara, penyebaran kuesioner, dan pengumpulan data sekunder. Pengambilan sampel menggunakan teknik probability sampling dengan metode simple random sampling, penelitian menggunakan analisis regresi berganda dengan jumlah sampel minimal 10 dari jumlah variabel. Dalam penelitian terdapat 7 variabel (1 variabel dan 6 variabel independen) maka jumlah sampel $10 \times 7=70$ responden menurut (Sugiyono 2013).

Dilihat dari sumber data pengumpulan data dapat menggunakan sumber primer dan sekunder. Sumber data primer adalah data yang diperoleh secara langsung tanpa melalui perantara, dalam penelitian ini petani dusun Wonotoro yang menjadi narasumber. Sumber data sekunder adalah data yang diperoleh secara tidak langsung seperti jurnal, penelitian terdahulu, publikasi Badan Pusat Statistik, kelompok tani, dan media informasi lain yang berhubungan dengan penelitian.

Metode analisis data yang digunakan dalam penelitian menggunakan persamaan regresi dengan model fungsi produksi Cobb-Douglas dan uji validitas, uji reliabilitas, serta uji penyimpangan terhadap asumsi klasik meliputi uji normalitas, uji heterokedastisitas, dan uji multikolinearitas. Semua pengujian menggunakan bantuan software SPSS.

Faktor-faktor yang memengaruhi produktivitas padi sawah dianalisis dengan model fungsi produksi CobbDouglass dengan model persamaan :

$\operatorname{Ln} \mathrm{Y}=\ln \mathrm{b} 0+\mathrm{b} 1 \operatorname{Ln} \mathrm{X} 1+\mathrm{b} 2 \operatorname{Ln} \mathrm{X} 2+\mathrm{b} 3$

$\mathrm{Ln} \mathrm{X} 3+\mathrm{b} 4 \mathrm{Ln} \mathrm{X} 4+\mathrm{b} 5 \mathrm{Ln} \mathrm{X} 5+\mathrm{b} 6 \mathrm{Ln}$ $\mathrm{X} 6+\varepsilon$

Keterangan :

$\mathrm{Y}=$ Produktivitas

$\mathrm{a}=$ Konstanta

$\mathrm{b}=$ Elastisitas faktor produksi $\mathrm{ke}-\mathrm{i}(\mathrm{i}=$ $1,2,3,4,5,6)$

$\mathrm{X} 1=\operatorname{Modal}(\mathrm{Rp})$

$\mathrm{X} 2=\operatorname{Bibit}(\mathrm{Kg})$ 
$\mathrm{X} 3$ = Lahan $(\mathrm{Ha})$

$\mathrm{X} 4=$ Tenaga Kerja $(\mathrm{HOK})$

$\mathrm{X} 5=$ Pupuk $(\mathrm{Kg})$

$\mathrm{X} 6=$ Pestisida $(\mathrm{Kg})$

$\mathrm{E}=$ Kesalahan

Persamaan yang telah diperoleh dilanjutkan uji statistik meliputi uji koefisien determinasi, uji simultan $\mathrm{F}$, dan uji parsial T.

\section{Analisis Kelayakan Usahatani}

Usahatani merupakan gambaran kegiatan ekonomi untuk menghasilkan output (penerimaan). Analisis Return Cost Ratio (R/C) digunakan untuk melihat tingkat keberhasilan usahatani menggunakan perbandingan antara penerimaan dan biaya.

$\mathrm{R} / \mathrm{C}=\mathrm{TR} / \mathrm{TC}$

Keterangan :

$\mathrm{R} / \mathrm{C}=$ Return Cost Ratio

$\mathrm{TR}=$ Penerimaan Usahatani Padi Sawah TC = Biaya Total Usahatani Padi Sawah Menurut Pujawan (2009), Benefit Cost Ratio adalah perbandingan antara nilai sekarang dari manfaat dengan nilai biaya sekarang. Rumus matematis untuk mencari $\mathrm{B} / \mathrm{C}$ ratio :

$\mathrm{B} / \mathrm{C}=\mathrm{FI} / \mathrm{TC}$

Keterangan :

$\mathrm{B} / \mathrm{C}=$ Benefit Cost Ratio

FI = Total Pendapatan Usahatani Padi

Sawah
$\mathrm{TC}=$ Total Biaya Produksi Usahatani

Padi Sawah

Model hipotesis kelayakan usahatani diambil dari rumus $\mathrm{B} / \mathrm{C}$ dan $\mathrm{R} / \mathrm{C}$ ratio, dimana jika $\mathrm{B} / \mathrm{C}>1$ layak diusahakan dan $\mathrm{R} / \mathrm{C}>1$ maka usahatani layak diusahakan.

\section{HASIL DAN PEMBAHASAN}

\section{Keadaan Umum Daerah Penelitian}

Kecamatan Sambi merupakan salah satu dari 22 kecamatan yang ada di Kabupaten Boyolali, Jawa Tengah. Wilayah penelitian ini berada di Desa Catur lebih tepatnya Dusun Wonotoro. Desa Catur berbatasan dengan Desa Ngaglik, di sebelah Selatan berbatasan dengan Desa Glintang, di sebelah Barat berbatasan dengan Desa Kaliwungu, dan sebelah Timur berbatasan dengan Desa Tawengan, dengan ketinggian berada di 185 mdpl dan memiliki luas wilayah 256.6350 ha dengan penggunaan lahan untuk sawah seluas 142,4500 ha dan tanah kering seluas 114,1850 ha. Dengan sistem irigasi yang baik dan air selalu tersedia dari waduk Wonotoro pertanian di desa Catur tergolong bagus.

\section{Karakteristik Responden}

Responden dalam penelitian ini berjumlah 70 orang petani padi sawah dusun Wonotoro. Karakteristik responden 
dikelompokkan berdasarkan jenis kelamin, usia, dan tingkat pendidikan.

\begin{tabular}{clcc} 
Tabel 1. Karakteristik Responden & \\
\hline No & $\begin{array}{l}\text { Karakteristik } \\
\text { responden }\end{array}$ & $\begin{array}{c}\text { Jumlah } \\
\text { (orang) }\end{array}$ & $\begin{array}{c}\text { Persentase } \\
(\%)\end{array}$ \\
\hline 1. & Jenis Kelamin & & \\
& Laki - laki & 62 & 89 \\
& Perempuan & 8 & 11 \\
& Jumlah & 70 & 100 \\
\hline 2. & Usia & & \\
& $41-50$ & 23 & 33 \\
& 51-60 & 25 & 36 \\
& 61-70 & 20 & 29 \\
& $>70$ & 2 & 3 \\
& Jumlah & 70 & 100 \\
\hline 3. & Pendidikan & & \\
& SD & 2 & 3 \\
& SMP & 18 & 26 \\
& SMA & 45 & 64 \\
& Sarjana & 5 & 7 \\
Jumlah & 70 & 100 \\
\hline
\end{tabular}

Sumber : Data primer diolah (2021)

Berdasarkan tabel 1 menunjukan bahwa jumlah responden laki-laki sebanyak 62 orang dengan persentase $89 \%$ lebih banyak dibandingkan dengan jumlah responden perempuan sebanyak 8 orang dengan persentase $11 \%$. Data tersebut menunjukan berdasarkan distribusi jenis kelamin bahwa budidaya tanaman padi sawah kebanyakan diusahakan oleh laki-laki.

Usia merupakan salah satu faktor yang memengaruhi tingkat produksi padi sawah. Berdasarkan hasil penelitian kelompok usia 51-60 tahun sebanyak 25 orang dan kelompok 41-50 sebanyak 23 orang,petani responden menunjukan usia produktif. Petani usia produktif memiliki kondisi yang optimal untuk meningkatkan hasil produksi.

Tabel 1 menunjukan bahwa tingkat pendidikan responden terbanyak adalah SMA dengan persentase $64 \%$ dan tingkat pendidikan terendah adalah SD dengan persentase sebesar 3\%. Hal ini menunjukan bahwa tingkat pendidikan di dusun Wontoro tergolong baik, tingkat pendidikan berpengaruh pada pola pikir seseorang dalam menangkap dan mengolah informasi sehingga kegiatan usahatani padi berkelanjutan.

\section{Uji Validitas}

Tabel 2. Hasil Uji Validitas Y

\begin{tabular}{clc}
\hline No & \multicolumn{1}{c}{ Variabel Penelitian } & r-hitung \\
\hline 1. & Produktivitas $(\mathrm{Y})$ & $-0,280$ \\
2. & Modal $\left(\mathrm{X}_{1}\right)$ & 0,903 \\
3. & Benih $\left(\mathrm{X}_{2}\right)$ & 0,877 \\
4. & Lahan $\left(\mathrm{X}_{3}\right)$ & 0,955 \\
5. & Tenaga Kerja $\left(\mathrm{X}_{4}\right)$ & 0,823 \\
6. & Pupuk $\left(\mathrm{X}_{5}\right)$ & 0,858 \\
7. & Pestisida $\left(\mathrm{X}_{6}\right)$ & 0,843 \\
\hline
\end{tabular}

Sumber : Data Primer diolah (2021)

Berdasarkan Tabel 2 hasil uji validitas dengan menggunakan uji Bivariate Pearson Correlation menentukan $\mathrm{r}-$ hitung $>\mathrm{r}-$ tabel pada signifikansi 5 $\%(0,235)$ sehingga dapat disimpulkan bahwa setiap butir pertanyaan pada kuesioner dinyatakan valid.

\section{Uji Reliabilitas}

Tabel 3. Hasil Uji Reliabilitas Y

\begin{tabular}{ccc}
\hline \multicolumn{3}{c}{ Reliability Statistics } \\
Cronbach's Alpha & N of Items \\
\hline .905 & \\
\hline \multicolumn{2}{c}{ Sumber : Data Primer diolah (2021) }
\end{tabular}


Tabel 3 menunjukan bahwa pernyataan dalam variabel penelitian mengenai produktivitas (Y), modal (X1), benih (X2), lahan (X3), tenaga kerja (X4), pupuk (X5), dan pestisida (X6) dinyatakan reliabel dengan nilai cronbach's Alpha lebih dari 0,7.

\section{Uji Normalitas}

Hasil pengujian normalitas pada Gambar 1 menunjukan data menyebar disekitar garis dan mengikuti garis diagonal, artinya pola data pada berdistribusi normal, didukung dengan uji normalitas menggunakan one sample Kolmogorov - Smirnoff Test diperoleh nilai Asymp. Sig sebesar 0,068 >0,05, maka dapat disimpulkan model regresi penelitian memenuhi asumsi normalitas.

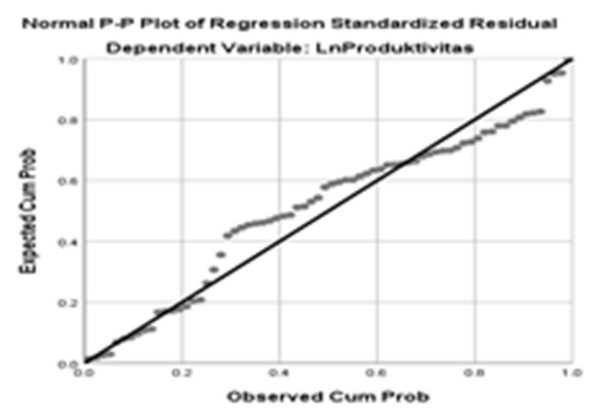

\section{Gambar 1. Normal P-Plot Hasil Uji} Normalitas.

\section{Uji Heteroskedastisitas}

Hasil pengujian heterokedasitas pada Gambar 4 menunjukan bahwa tidak menyebar dan membentuk pola tertentu, artinya data pada penelitian tidak mengalami gejala heteroskedastisitas. Maka dapat disimpulkan model regresi penelitian memenuhi asumsi heteroskedastisitas.

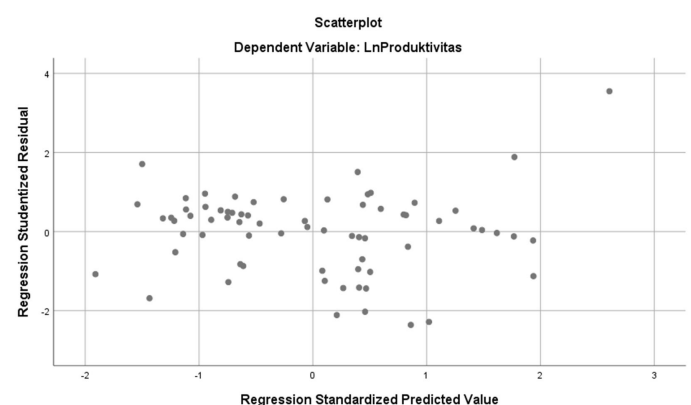

Gambar 2. Scatterplot Hasil Uji Heterokedastisitas

\section{Uji Multikolinearitas}

Uji Multikolinearitas digunakan untuk menguji model regresi adanya korelasi antar variabel independen. Model yang baik tidak terjadi korelasi jika korelasi antara yang tinggi diantara variabel bebas, untuk mengukur multikolinearitas yang umum dipakai adalah tolerance 0,10 atau sama dengan nilai VIF di atas 10.

\section{Tabel 4. Uji Multikolinearitas Y}

\begin{tabular}{clcc}
\hline No & \multicolumn{1}{c}{$\begin{array}{c}\text { Variabel } \\
\text { Penelitian }\end{array}$} & Tolerance & VIF \\
\hline 1. & Modal $\left(\mathrm{X}_{1}\right)$ & 0,226 & 4,432 \\
2. & Benih $\left(\mathrm{X}_{2}\right)$ & 0,247 & 4,050 \\
3. & Lahan $\left(\mathrm{X}_{3}\right)$ & 0,102 & 9,818 \\
4. & Tenaga Kerja & 0,336 & 2,977 \\
& (X $\left._{4}\right)$ & & \\
5. & Pupuk $\left(\mathrm{X}_{5}\right)$ & 0,353 & 2,833 \\
6. & Pestisida $\left(\mathrm{X}_{6}\right)$ & 0,389 & 2,569 \\
\hline
\end{tabular}

Sumber : Data primer diolah (2021)

Hasil pengujian multikolinearitas pada Tabel 4 menunjukan bahwa tidak terdapat gejala multikolinearitas dalam 
variabel penelitian menunjukan bahwa nilai tolerance $>0,1$ dan nilai VIF $<10$, maka dapat disimpulkan tidak terjadi multikolinearitas antar variabel independen.

\section{Analisis Fungsi Produksi}

Tabel 5 Hasil Analisis Cobb-Douglass antara Modal (X1), Benih (X2), Luas Lahan (X3), Tenaga Kerja (X4), Pupuk (X5), Pestisida (X6) Terhadap Produktivitas Padi di Wonotoro.

\begin{tabular}{lcccc}
\hline Variabel Penelitian & Koefisien Regresi (B) & Std. Error & t-test & Sig. \\
\hline (Constant) & 3,394 & 0,874 & 3,884 & 0,000 \\
LnModal $\left(\mathrm{X}_{1}\right)$ & $-0,007$ & 0,053 & $-0,126$ & 0,900 \\
LnBenih $\left(\mathrm{X}_{2}\right)$ & 0,024 & 0,051 & 0,479 & 0,633 \\
LnLuas Lahan $\left(\mathrm{X}_{3}\right)$ & $-0,209$ & 0,073 & $-2,867$ & 0,006 \\
LnTenaga Kerja $\left(\mathrm{X}_{4}\right)$ & 0,124 & 0,051 & 2,449 & 0,017 \\
LnPupuk $\left(\mathrm{X}_{5}\right)$ & 0,002 & 0,040 & 0,054 & 0,957 \\
LnPestisida $\left(\mathrm{X}_{6}\right)$ & 0,045 & 0,039 & 1,159 & 0,251 \\
F-test & 3,362 & Sig. & 0,006 & \\
F-tabel & 2,25 & t-tabel & 1,998 & \\
R & 0,493 & & & \\
$R$-square & 0,243 & & & \\
Adjusted R-square & 0,170 & & & \\
\hline Sumber : Data prim & & & & \\
\end{tabular}

Sumber : Data primer diolah (202

Berdasarkan hasil analisis uji analisis fungsi produksi Cobb-Douglass pada Tabel 5 diperoleh persamaan sebagai berikut :

$\operatorname{LnY}=3,394-0,007 \operatorname{LnX} 1+0,024 \operatorname{LnX} 2$

$-0,209 \operatorname{LnX} 3+0,124 \operatorname{LnX} 4+$

$0,002 \operatorname{LnX} 5+0,045 \operatorname{LnX} 6+\mathrm{e}$

Dari persamaan di atas dapat dilihat bahwa hasil nilai konstanta sebesar 3,394 pada fungsi produksi padi menunjukan bahwa jika variabel bebas (modal, benih, luas lahan, tenaga kerja, pupuk, dan pestisida) dianggap konstan maka produktivitas padi adalah 3,394. Hasil koefisien regresi pada variabel
Hasil analisis fungsi produksi menggunakan metode Cobb-Douglass pengaruh antara modal (X1), benih (X2), luas lahan (X3), tenaga kerja (X4), pupuk (X5), pestisida (X6) terhadap produktivitas padi di Wonotoro disajikan pada Tabel 5 . 
memiliki nilai koefisien regresi sebesar 0,124 artinya setiap penambahan satu nilai tenaga kerja akan meningkatkan produktivitas (Y) sebesar 0,124 dengan asumsi variabel bebas lain konstan. Dari hasil koefisien regresi pupuk (X5) memiliki nilai koefisien regresi sebesar 0,002 artinya setiap penambahan satu nilai pupuk akan meningkatkan produktivitas (Y) sebesar 0,002 dengan asumsi variabel bebas yang lain konstan. Variabel pestisida (X6) memiliki nilai koefisien regresi sebesar 0,045 artinya setiap penambahan satu nilai pestisida akan meningkatkan produktivitas (Y) sebesar 0,045 dengan asumsi variabel bebas yang lain konstan.

Berdasarkan hasil uji f pada tabel 5 diperoleh nilai F-test sebesar 3,362 > Ftabel 2,25 dengan signifikansi sebesar $0,006<0,05$ yang berarti bahwa variabel modal, benih, luas lahan, tenaga kerja, pupuk, dan pestisida secara bersamasama memiliki pengaruh signifikan terhadap produktivitas padi. Modal, benih, luas lahan, tenaga kerja, pupuk, damn pestisida yang digunakan dalam usahatani padi sawah mampu mendukung produktivitas padi.

Berdasarkan hasil uji koefisien determinasi $\left(\mathrm{R}^{2}\right)$ menunjukan bahwa modal, benih, luas lahan, tenaga kerja, pupuk, dan pestisida memiliki nilai Rsquare sebesar 0,243 atau 24,3\% yang berarti bahwa dalam penelitian ini perubahan produktivitas padi sebesar $24,3 \%$ dipengaruhi oleh perubahan variabel modal, benih, luas lahan, tenaga kerja, pupuk, dan pestisida sedangkan sisanya dijelaskan oleh faktor-faktor lain seperti kondisi alam, hama dan penyakit yang tidak dijelaskan dalam model penelitian. Berdasarkan hasil uji $t$ dapat diketahui bahwa secara parsial diketahui bahwa benih, tenaga kerja, pupuk, dan pestisida berpengaruh positif $(\mathrm{p}<0,05)$ terhadap produktivitas padi sawah sedangkan modal dan luas lahan berpengaruh negatif $(p>0,05)$ terhadap produktivitas padi.

\section{Modal (X1)}

Dilihat pada Tabel 5 nilai koefisien regresi pada variabel modal (X1) diperoleh nilai sebesar $-0,007$ dengan nilai t-test $-0,126<$ t-tabel 1,998 dan sig. 0,900 $>0,05$ dapat disimpulkan bahwa modal tidak memiliki pengaruh secara individual atau parsial terhadap produktivitas padi di dusun Wonotoro. Tanda negatif menunjukan pengaruh tidak searah. Pengaruh modal yang tidak signifikan menunjukan bahwa modal yang digunakan tidak memengaruhi produktivitas padi di dusun Wonotoro. 
Menurut Ariessi dan Utama (2017), ketersedian jumlah modal yang tepat sesuai dengan kebutuhan dalam produksi usahatani akan memengaruhi produktivitas pertanian. Kurangnya pengetahuan mengenai penghitungan modal secara tepat seringkali membuat petani melewatkan perhitungan ekonomi yang seharusnya dilakukan, terlalu banyak biaya implisit yang terlewat menghasilkan bias pada perhitungan hasil usahatani.

\section{Benih (X2)}

Hasil analisis parsial yang telah dilakukan diperoleh nilai koefisien regresi sebesar 0,024 dengan nilai t-test $0,0479<$ t-tabel 1,998 dan sig. $0,0633>$ 0,05 yang dapat disimpulkan bahwa tidak memiliki pengaruh secara individual atau parsial terhadap produktivitas padi di dusun Wonotoro tanda positif menunjukan pengaruh searah. Pengaruh yang tidak signifikan terhadap produktivitas padi menunjukan bahwa jumlah benih yang digunakan tidak memengaruhi produktivitas. Hal ini didukung hasil penelitian dari yang menunjukan bahwa variabel jumlah benih tidak berpengaruh signifikan terhadap produktivitas padi. Benih yang bermutu menjanjikan hasil panen yang baik dan bermutu diikuti dengan sistem agronomi dan input teknologi yang baik (Lybaws, et. al., 2017). Jumlah penggunaan benih bermutu yang sesuai anjuran mampu mengurangi faktor risiko kegagalan panen dan meningkatkan produktivitas.

\section{Luas Lahan (X3)}

Dilihat pada Tabel 5 hasil uji luas lahan diperoleh nilai koefisien regresi sebesar $-0,0209$ dengan nilai t-test $-2,587$ $>$ t-tabel 1,998 dan sig. 0,006 < 0,05 yang dapat disimpulkan memiliki pengaruh secara individual atau parsial terhadap produktivitas padi, tanda negatif menunjukan pengaruh tidak searah. Tanda negatif menunjukan pengaruh tidak searah. Hasil penelitian menunjukan bahwa semakin besar luas lahan akan menurunkan produktivitas padi. Hal ini sejalan dengan penelitian yang dilakukan Panjaitan (2019) yang menunjukan bahwa penggunaan lahan berpengaruh negatif dan nyata pada taraf $90 \%$ terhadap produksi usahatani padi. Namun, berbeda dengan penelitian yang dilakukan Arimbawa dan Widanta (2017) yang menunjukan bahwa luas lahan berpengaruh terhadap produktivitas padi. Pengaruh yang negatif menunjukan bahwa lahan berada pada daerah yang irasional, dimana penambahan luas lahan dapat menurunkan produktivitas usahatani di 
dusun Wonotoro. Luas lahan berpengaruh negatif terjadi di daerah penelitian akibat penurunan kualitas lahan dan kandungan unsur hara sehingga hasil yang diberikan tidak maksimal. Menurut Dariah, et.al., (2015), kualitas tanah yang relatif rendah merupakan salah satu penyebab rendahnya produktivitas lahan pertanian. Selain karakteristik lahan, degradasi atau penurunan kualitas lahan pertanian Indonesia dapat disebabkan oleh faktor alam maupun faktor manusia yang tidak melakukan sistem pengolahan lahan secara tepat dan berkelanjutan. Penggunaan pembenahan tanah merupakan cara yang dapat ditempuh untuk mempercepat proses pemulihan kualitas lahan, namun perlu dilakukan pemilihan bahan pembenah tanah yang sesuai dengan karakteristik tanah.

\section{Tenaga Kerja (X4)}

Hasil uji tenaga kerja diperoleh nilai koefisien regresi sebesar 0,124 dengan nilai t-test 2,449>t-tabel 1,998 dan sig. $0,017<0,05$ yang dapat disimpulkan memiliki pengaruh secara individual atau parsial terhadap produktivitas padi di dusun Wonotoro. Tanda positif menunjukan pengaruh searah. Hasil penelitian menunjukan bahwa semakin banyak tenaga kerja yang digunakan akan meningkatkan produktivitas padi. Hal ini sejalan dengan hasil penelitian Khakim, Hastuti, dan Widiyani (2013) yang menunjukan bahwa tenaga kerja berpengaruh secara positif dan signifikan terhadap produksi padi di Jawa Tengah yang berarti apabila tenaga kerja semakin besar maka produktivitas semakin besar. Ketersediaan jumlah tenaga kerja yang tepat dengan kebutuhan dalam produksi usahatani akan memengaruhi produktivitas pertanian. Rata-rata pendidikan petani di daerah penelitian di daerah penelitian sudah dapat mendukung kegiatan pengelolaan usahatani karena penerimaan informasi sudah lebih baik.

\section{Pupuk (X5)}

Dilihat pada Tabel 5 hasil uji pupuk diperoleh nilai koefisien regresi 0,002 dengan nilai t-test $0,054<\mathrm{t}$-tabel 1,998 dan sig. $0,957>0,05$ yang dapat disimpulkan tidak memiliki pengaruh secara individual atau parsial terhadap produktivitas padi di dusun Wonotoro. Tanda positif menunjukan pengaruh yang searah. Hasil penelitian yang menunjukan bahwa pupuk tidak berpengaruh secara signifikan terhadap produktivitas padi. Jumlah pupuk yang digunakan dalam kegiatan usahatani tidak akan memengaruhi peningkatan produktivitas. 
Penelitian yang dilakukan oleh Akbar, et. al., (2018) menunjukan bahwa penggunaan pupuk urea tidak menunjukan pengaruh signifikan terhadap produktivitas padi. Petani di dusun Wonotoro rata-rata menggunakan pupuk sebanyak 363,43 kg/ha. Anhar et. al., (2016), menyatakan bahwa pemerintah merekomendasikan penggunaan pupuk urea sebanyak 200$250 \mathrm{~kg} / \mathrm{ha}$ di lahan normal. Menurut Suharyanto et. al., (2015), hal ini justru berdampak negatif terhadap lingkungan dan meningkatkan biaya produksi. Tanaman akan menyerap pupuk sesuai kebutuhan unsur haranya, pentingnya mengetahui karakter jenis padi yang ditanam dan lahan yang digunakan dapat menentukan jumlah pupuk agar produktivitas maksimal.

\section{Pestisida (X6)}

Berdasarkan hasil uji pestisida pada Tabel 5 diperoleh nilai koefisien regresi 0,045 dengan nilai t-test $1,159<$ t-tabel 1,998 dan sig. 0,251>0,05 yang dapat disimpulkan tidak memiliki pengaruh secara individual atau parsial terhadap produktivitas padi di dusun Wonotoro. Tanda positif menunjukan pengaruh yang searah. Hasil penelitian menunjukan bahwa pestisida tidak berpengaruh secara signifikan terhadap produktivitas padi. Hal ini didukung oleh penelitian Lybaws, et. al., (2017) yang menunjukan bahwa penggunaan pestisida tidak berpengaruh nyata terhadap produksi usahatani padi ladang. Rata-rata penggunaan pestisida oleh petani dusun Wonotoro adalah 146.141 per hektar, tidak berpengaruhnya pestisida disebabkan faktor cuaca dan banyak penyakit yang menyerang tanaman padi.

\section{Analisis Kelayakan Usahatani}

Analisis kelayakan usahatani padi di dusun Wonotoro dilakukan untuk melihat sejauh mana manfaat yang dapat diperoleh dalam melaksanakan kegiatan usaha. Analisis kelayakan usahatani padi di dusun Wonotoro menggunakan alat ukur Revenue Cost Ratio (R/C Ratio) dan Benefit Cost Ratio (B/C Ratio). Hasil analisis kelayakan usahatani padi di dusun Wonotoro (Tabel 6).

Dari Tabel 6 dapat diketahui hasil perhitungan analisis kelayakan usahatani padi di dusun Wonotoro. Hasil analisis menunjukkan bahwa nilai $\mathrm{R} / \mathrm{C}$ ratio sebesar 1,77 lebih besar dari 1, artinya usahatani padi di dusun Wonotoro layak untuk diusahakan. Nilai R/C ratio sebesar 1,77 artinya setiap $\mathrm{Rp} 1,-$ yang dikeluarkan oleh petani maka akan diperoleh keuntungan sebesar $\mathrm{Rp}$ 1,77. 
Hasil analisis menunjukkan bahwa nilai $\mathrm{B} / \mathrm{C}$ ratio sebesar 1,06 lebih besar dari 1 , artinya usahatani padi di dusun Wonotoro layak untuk diusahakan. Nilai $\mathrm{B} / \mathrm{C}$ ratio sebesar 1,06 artinya setiap $\mathrm{Rp}$ 1,- yang dikeluarkan oleh petani dalam usahatani padi, maka akan diperoleh keuntungan sebesar Rp 1,06. Pada, tahun 2019 hasil panen padi di daerah penelitian mengalami penurunan hasil yang rata-rata hanya 3 ton dengan produktivitas $81,60 \mathrm{kw} / \mathrm{ha}$. Namun, hasil penelitian menunjukan bahwa usahatani masih layak diusahakan dan dikembangkan untuk meningkatkan pendapatan petani.

Tabel 6. Analisis Kelayakan Usahatani Padi di Wonotoro

\begin{tabular}{|c|c|c|}
\hline No & Keterangan & $\begin{array}{c}\text { Usahatani Padi/Musim } \\
\text { Tanam }\end{array}$ \\
\hline \multirow[t]{2}{*}{1} & Jumlah & 2480,57 \\
\hline & Produksi $(\mathrm{Kg})$ & \\
\hline 2 & $\begin{array}{l}\text { Harga gabah } \\
(\mathrm{Rp} / \mathrm{Kg})\end{array}$ & 4.600 \\
\hline \multirow[t]{2}{*}{3} & Jumlah & 15.414 .857 \\
\hline & $\begin{array}{l}\text { Penerimaan } \\
\text { (Rp) }\end{array}$ & \\
\hline \multirow[t]{3}{*}{4} & Biaya Total & 8.723 .714 \\
\hline & $\begin{array}{l}\text { Biaya Eksplisit } \\
\text { (Rp) }\end{array}$ & 6.143 .571 \\
\hline & $\begin{array}{l}\text { Biaya Implisit } \\
(\mathrm{Rp})\end{array}$ & 2.580 .143 \\
\hline 5 & $\begin{array}{l}\text { Pendapatan } \\
\text { (Rp) }\end{array}$ & 9.271 .286 \\
\hline 6 & $\begin{array}{l}\text { Keuntungan } \\
\text { (Rp) }\end{array}$ & 6.691 .143 \\
\hline \multirow[t]{3}{*}{7} & Kelayakan & \\
\hline & $\mathrm{R} / \mathrm{C}$ ratio & 1,77 \\
\hline & $\mathrm{B} / \mathrm{C}$ ratio & 1,06 \\
\hline
\end{tabular}

Sumber : Data Primer diolah (2021)

\section{KESIMPULAN DAN SARAN}

\section{Kesimpulan}

Faktor produksi seperti modal, benih, pupuk, dan pestisida tidak memiliki pengaruh secara signifikan terhadap produktivitas, sedangkan luas lahan dan tenaga kerja memiliki pengaruh secara signifikan terhadap produktivitas pada usahatani padi sawah di dusun Wontoro.

Berdasarkan hasil perhitungan kelayakan usahatani tanaman padi sawah, diperoleh $\mathrm{R} / \mathrm{C}$ ratio sebesar 1,77 dan nilai $\mathrm{B} / \mathrm{C}$ ratio sebesar 1,06 . Hal ini berarti untuk setiap Rp 1 yang dikeluarkan petani akan memberikan keuntungan sebesar Rp 1,77 dan Rp 1,06. Sesuai kriteria kelayakan usahatani yang diperoleh yaitu $\mathrm{R} / \mathrm{C}$ ratio dan $\mathrm{B} / \mathrm{C}$ ratio $>1$, maka kegiatan usahatani layak diusahakan dari aspek finansial.

\section{Saran}

Berdasarkan hasil penelitian saran yang dapat diberikan adalah penggunaan faktor produksi modal yang di keluarkan secara tepat agar kegiatan usahatani dapat menghasilkan hasil maksimal. Penggunaan faktor produksi pupuk yang sesuai dengan anjuran pemerintah untuk meningkatkan hasil panen maka kegiatan produktivitas maksimal. Peran penyuluh harus lebih ditingkatkan agar 
keberlangsungan kegiatan budidaya padi lebih meningkat.

\section{DAFTAR PUSTAKA}

Akbar, Ilham, Kustopo Budiraharjo, dan Mukson Mukson. (2018). "Analisis Faktor-Faktor Yang Memengaruhi Produktivitas Padi Di Kecamatan Kesesi, Kabupaten Pekalongan." Agrisocionomics: Jurnal Sosial Ekonomi Pertanian 1(2):99.

Anhar, Ridwan, Erita Hayati, Mahasiswa Agroteknologi, Fakultas Pertanian, Universitas Syiah, Dosen Agroteknologi, Fakultas Pertanian, Universitas Syiah, dan Darussalam Banda Aceh. (2016). "Pengaruh dosis pupuk urea terhadap pertumbuhan dan produksi plasma nutfah padi lokal asal aceh." Jurnal Kawista Agroteknologi 1(1):30-36.

Ariessi, Nian Elly, dan Made Suyana Utama. (2017). "Pengaruh modal, tenaga kerja dan modal sosial terhadap produktivitas petani di Kecamatan Sukawati Kabupaten Gianyar." Piramida 8(2):97-107.

Arimbawa, Putu Dika, dan A. .. Bagus Putu Widanta. (2017). "Pengaruh Luas Lahan, Teknologi dan Pelatihan Terhadap Pendapatan Petani Padi dengan Produktivitas sebagai Variabel Intervening di Kecamatan Mengwi." Arimbawa, Dika Putu 6:1601-27.

Badan Pusat Statistik. (2016). "Provinsi Jawa Tengah Dalam Angka 2016."

Badan Pusat Statistik. (2018). "Provinsi Jawa Tengah Dalam Angka 2018." 283.

Badan Pusat Statistik. (2019). "Kecamatan Boyolali Dalam Angka 2019."

Dariah, Ai, S. Sutono, Neneng L.
Nurida, Wiwik Hartatik, Etty Pratiwi, Balai Penelitian, Tanah Jl, Tentara Pelajar, dan Bogor Email. (2015). "Pembenah Tanah untuk Meningkatkan Produktivitas Lahan Pertanian." Jurnal Sumberdaya Lahan 9(2):67-84.

Fink Lybaws, Damel, Zulkifli Alamsyah, Yanuar Fitri. (2017). "Analisis Efisiensi Ekonomi Penggunaan Faktor-Faktor Produksi Pada Usahatani Padi Ladang Di Kecamatan Pauh Kabupaten Sarolangun."

Khakim, Ludfil, Dewi Hastuti, dan Aniya Widiyani. (2013). "Pengaruh luas lahan, tenaga kerja, penggunaan benih, dan penggunaan pupuk terhadap produksi padi di Jawa Tengah.” Jurnal Ilmu-ilmu Pertanian Mediagro 9(1):71-79.

Mahananto, Sutrisno Salyo, Ananda Chandra F. (2009). "Faktor-Faktor Yang Memengaruhi Produksi Padi Studi Kasus di Kecamatan Nogosari , Boyolali, Jawa Tengah.” Wacana 12(1):179-91.

Panjaitan, Faisal Azhari Baldan. (2019). "Analisis Efisiensi Faktor Produksi Usahatani Padi Sawah Di Kabupaten Langkat Provinsi Sumatera Utara". Tesis. Universitas Sumatera Utara.

Pujawan, I. Nyoman. (2009). Ekonomi Teknik Edisi Kedua Jilid Pertama. surabaya: Guna Widya.

Rustam, Wafda. (2014). "Analisis Pendapatan dan Kelayakan Usahatani Padi Sawah di Desa Randomayang Kecamatan Bambalamotu Kabupaten Mamuju Utara." E-Jurnal Agrotekbis 2(6):634-38.

Sugiyono. (2013). Metode Pendidikan Pendekatan Kuantitatif, Kualitatif, dan R\&D. Bandung: Alfabeta.

Suharyanto, Jangkung H. Mulyo, Dwidjono H. Darwanto, dan Sri 
Widodo. (2015). "Analisis Produksi dan Efisiensi Pengelolaan Tanaman Terpadu Padi Sawah di Provinsi Bali Production and Efficiency Analysis of the Integrated Crop." Penelitian Pertanian Tanaman Pangan 34(2):131-44.

Manurung, Wahyudi, Muhammad Fajar, dan Noviar. (2020). "Pemodelan Produktivitas Padi Dengan Menggunakan Generalized Additive Models Di Provinsi Banten." Jurnal Lebesgue : Jurnal Ilmiah Pendidikan Matematika, Matematika dan Statistika 1(2):105-12.
Yuliana, T. Ekowati, dan M. Handayani. (2017). "Efisiensi Alokasi Penggunaan Faktor Produksi pada Usahatani Padi di Kecamatan Wirosari, Kabupaten Grobogan." AGRARIS: Journal of Agribusiness and Rural Development Research 3(1). 